\title{
Phylogeographic structure and northward range expansion in the barnacle Chthamalus fragilis
}

Annette F. Govindarajan, Filip Bukša, Katherine Bockrath, John P. Wares, Jesús Pineda

The barnacle Chthamalus fragilis is found along the US Atlantic seaboard historically from the Chesapeake Bay southward, and in the Gulf of Mexico. It appeared in New England circa 1900 coincident with warming temperatures, and is now a conspicuous member of rocky intertidal communities extending through the northern shore of Cape Cod, Massachusetts. The origin of northern $C$. fragilis is debated. It may have spread to New England from the northern end of its historic range through larval transport by ocean currents, possibly mediated by the construction of piers, marinas, and other anthropogenic structures that provided new hard substrate habitat. Alternatively, it may have been introduced by fouling on ships originating farther south in its historic distribution. Here we examine mitochondrial cytochrome c oxidase I sequence diversity and the distribution of mitochondrial haplotypes of $C$. fragilis from 11 localities ranging from Cape Cod, to Tampa Bay, Florida. We found significant genetic structure between northern and southern populations. Phylogenetic analysis revealed three well-supported reciprocally monophyletic haplogroups, including one haplogroup that is restricted to New England and Virginia populations. While the distances between clades do not suggest cryptic speciation, selection and dispersal barriers may be driving the observed structure. Our data are consistent with an expansion of $C$. fragilis from the northern end of its mid- $19^{\text {th }}$ century range into Massachusetts. 
2 Phylogeographic structure and northward range expansion in the barnacle Chthamalus fragilis

3

4 Annette F. Govindarajan, ${ }^{* 1}$, Filip Bukša ${ }^{1,2}$, Katherine Bockrath ${ }^{3}$, John P. Wares ${ }^{3,4}$, Jesús Pineda ${ }^{1}$

$5 \quad{ }^{1}$ Biology Department, Woods Hole Oceanographic Institution, Woods Hole, MA, 02543, USA

6 ${ }^{2}$ Department of Biology, University of Zagreb, Croatia

${ }^{3}$ Department of Genetics, University of Georgia, Athens, GA, USA

8

${ }^{4}$ Odum School of Ecology, University of Georgia, Athens, GA, USA

9

10

11 *Corresponding author; Redfield 230 MS\# 33, Biology Department, Woods Hole Oceanographic

12 Institution, Woods Hole, MA, 02543; 508-289-3308; afrese@whoi.edu

13 
Introduction

Evaluation of population genetic discontinuities and range boundaries in coastal marine species

16 is essential for understanding the consequences of anthropogenic stressors like climate change which

17 may be driving range shifts, particularly poleward range expansions (e.g., Barry et al., 1995; Zacherl,

18 Gaines \& Lonhart, 2003; Dawson et al., 2010; Harley, 2011). Along the Atlantic coast of the US, Cape

19 Hatteras and Cape Cod are especially important boundary regions (Pappalardo et al., 2014). However,

20 because these boundaries are permeable (e.g., many species traverse the boundaries; Pappalardo et al.,

21 2014), as are other coastal boundary regions for nearshore species (e.g., Valentine, 1966), it is

22 necessary to evaluate each species individually. The intertidal barnacle Chthamalus fragilis is currently

23 found along the eastern United States, extending from the Gulf of Mexico to the Atlantic coast

24 northward up to Massachusetts (Wells, 1966; Zullo, 1963; Carlton, Newman \& Pitombo, 2011), and is

25 thought to be experiencing a northward range expansion linked to warmer temperatures (Carlton,

26 Newman \& Pitombo, 2011). Prior to the late $19^{\text {th }}$ century, C. fragilis was observed from the

27 Chesapeake Bay area and southward. It was first observed in New England (Woods Hole,

28 Massachusetts) in 1898, and subsequently was observed in other locations south of Cape Cod, in

29 Buzzards Bay and Vineyard Sound (Carlton, Newman \& Pitombo, 2011). More recently it is found

30 along the north shore of Cape Cod, from the outer Cape (Provincetown) to Sandwich at the northern

31 end of the Cape Cod Canal (Zullo 1963; Carlton 2002; Wethey, 2002; Jones, Southward \& Wethey,

32 2012). C. fragilis is a conspicuous species occupying the easily accessible upper intertidal, so it is

33 unlikely that an earlier northern presence was overlooked, particularly as the Woods Hole region has a

34 long history of faunal surveys.

The source of the northern $C$. fragilis populations is controversial. It is unknown if the barnacles dispersed via natural (e.g., ocean currents) or anthropogenic vectors (e.g., ship hull fouling),

37 or both. C. fragilis possesses a typical biphasic life cycle, with the potential for long distance dispersal. 
38 Adults are hermaphroditic with internal fertilization and are capable of self-fertilization (Barnes \&

39 Barnes, 1958). Thus, clusters of adults are not required for reproduction as in many barnacles (Crisp,

40 1950). Larvae are released into the water, typically in the summer (Lang \& Ackenhusen-Johns, 1981),

41 where they pass through 6 naupliar stages and a non-feeding cyprid stage. In chthamalids, the

42 planktonic period may last up to three weeks or more (Miller et al., 1989), allowing ample time for

43 larval transport by ocean currents. Cyprids settle on hard intertidal substrata and metamorphose into the 44 adult form.

C fragilis settles on artificial surfaces, and thus has a high potential for dispersal by anthropogenic transport. Sumner (1909) suggested that the relatively sudden appearance of C. fragilis in Woods Hole, MA was due to human introduction. In support of this hypothesis, Carlton et al. (2011) points out that Woods Hole was home to the Pacific Guano Company between 1863 and 1889, which received potentially fouled ships from South Carolina, the type locality for C. fragilis, and elsewhere.

50 The construction of structures such as docks, pilings, and seawalls may have provided suitable habitats 51 along the mostly sandy shoreline south of Connecticut, also facilitating range expansion (e.g., Jones, 52 Southward \& Wethey, 2012). The New England region has experienced warmer temperatures since the 1850s (Carlton,

54 2002), and warmer temperatures may have facilitated the successful dispersal and establishment of $C$.

55 fragilis by releasing it from competition with the less heat-tolerant barnacle Semibalanus balanoides in

56 the upper intertidal (Wethey, 2002). In these intertidal areas, C. fragilis is found higher, where $S$.

57 balanoides, the better competitor, cannot survive (Wethey, 2002). The goals of this study were to investigate the phylogeographic structure of C. fragilis and gain

59 insight into the origin of northern C. fragilis populations by comparing mitochondrial cytochrome c

60 oxidase (COI) haplotypes from several locations in Massachusetts and Rhode Island with those

61 obtained from locations farther south, in Virginia, South Carolina, Georgia, and Florida. Thus, 
62 sampling covered a $\sim 2000 \mathrm{~km}$ range (minimum linear separation). While confirming the source of

63 populations that are cryptogenic (i.e., of unknown origin) can be difficult, the existence of private

64 haplotypes shared between the northern populations and a subset of southern populations may indicate

65 the colonization pathway (Geller, Darling \& Carlton, 2010). For example, private haplotypes shared

66 between northern and South Carolina barnacles may support the idea that barnacles arrived through

67 transport associated with the Woods Hole guano industry (Carlton, Newman \& Pitombo, 2011).

68 Alternatively, private haplotypes shared only between northern and Chesapeake Bay - area barnacles

69 (at the northern end of their historic range) may suggest a range expansion. We compare genetic

70 diversity and the distribution of mitochondrial haplotypes from barnacles ranging from Massachusetts

71 to Florida, and demonstrate significant genetic structuring between northern and southern populations.

72 We discuss the implications of these patterns for a genetic break near Cape Hatteras and the origin of

73 northern C. fragilis.

\section{Materials \& Methods}

We collected 108 Chthamalus fragilis individuals from 11 sites along the Atlantic and Gulf coasts of North America (Table 1). We extracted genomic DNA using DNEasy Blood and Tissue and

78 Puregene kits (Qiagen) and amplified the mitochondrial cytochrome c oxidase I (COI) gene using

79 standard primers (Folmer et al., 1994) and protocols. We ran $25 \mu \mathrm{l} \mathrm{PCR} \mathrm{reactions} \mathrm{containing} 1 \mu \mathrm{l}$ of

80 genomic DNA in a PCR program consisting of an initial denaturation at $95^{\circ}$ for 3 minutes; 35 cycles of

$8195^{\circ}$ for $30 \mathrm{~s}, 48^{\circ}$ for $30 \mathrm{~s}$, and $72^{\circ}$ for 1 minute; and a final extension at $72^{\circ}$ for 5 minutes. We

82 visualized PCR products on a 1.5\% agarose gel stained with GelRed (Biotium). PCR products were

83 purified using Qiaquick PCR Purification kits (Qiagen) and quantified using a Nanodrop 2000

84 spectrophotometer. Purified products were sent to MWG Eurofins Operon for sequencing in both

85 directions. 
We assembled chromatograms and confirmed sequence quality using Geneious v. 7.1.7

87 (Biomatters). Sequences were aligned using ClustalW (Larkin et al., 2007) with default parameters

88 using the Geneious platform. The alignment was confirmed by eye and translated into amino acid

89 sequences to verify that no pseudogenes were present. Sequences were deposited in GenBank

$90 \quad($ KP898760 - KP898867)

$91 \quad$ Nucleotide diversity, haplotype diversity, Tajima's D and Fu's Fs were calculated using DnaSP

92 (Librado \& Rozas, 2009). An AMOVA was performed using Arlequin (Excoffier \& Lischer, 2010).

93 To examine relationships between haplotypes, we conducted a Bayesian analysis using Mr.Bayes,

94 accessed through Geneious. The best-fit model for the Bayesian analysis was selected using the

95 corrected Akaike Information Criterion (AICc) with jModeltest 2.1.6 (Guindon \& Gascuel, 2003;

96 Darriba \& Posada, 2014), based on 3 substitution schemes for compatibility with Geneious. The

97 settings in Mr. Bayes were Nst = 6, rates=invgamma, ngammacat=4. 1,100,000 generations, sampling

98 frequency $=1000$, number of chains $=4$; temperature $=0.2$, and burnin $=100$.

We examined the geographic distribution of the major well-supported haplogroups recovered in

100 the Bayesian analysis. A Mantel test was conducted using the Isolation By Distance Web Service v.

1013.23 (Jensen et al., 2005) to test for isolation by distance. Pairwise geographic distances were

102 calculated using Google Earth following the coast with the segments connecting two shoreline points $\leq$

$10320 \mathrm{~km}$, reflecting plausible larval transport routes and dispersal distances. We also compared

104 intraspecific divergences between sequences from the major haplogroups with C. proteus, a cryptic

105 sibling species of $C$. fragilis (Genbank accession numbers FJ858021-FJ858040, Wares 2001).

106

107 Results

108 After trimming the ends and removing 6 positions with ambiguous base calls, our alignment

109 was 613 base pairs, with 93 unique sequences (haplotypes), and 110 polymorphic sites, of which 58 
110 were parsimony informative. In the amino acid alignment (which included the 6 positions excluded in

111 the nucleotide alignment), there were three amino acid substitutions: a valine for an alanine in position

1126 in a Charleston, South Carolina sequence; a valine for an isoleucine in position 55 for a Woods Hole,

113 Massachusetts sequence, and an alanine for a threonine in position 157 for a Summerland Key, Florida 114 sequence.

115 For all sites, haplotype diversity was high and Tajima's D and Fu's Fs were negative (Table 1),

116 which may indicate population expansion or purifying selection. However, there were no trends with

117 latitude and none of the Tajima's D values were significant. $\mathrm{F}_{\mathrm{ST}}$ and AMOVA results showed

118 significant genetic structure particularly between distant sites (Table 2), with $\sim 14 \%$ of the variation

119 among populations and $\sim 86 \%$ of the variation within populations (Table 3 ). The best-fit model selected

120 using the AICc was $\mathrm{HKY}+\mathrm{I}+\mathrm{G}$. A Bayesian analysis conducted with this model revealed three distinct,

121 well-supported haplogroups (i.e., clades) (Figure 1). A neighbor-joining tree based on HKY distances

122 also uncovered these three haplogroups (Figure 1), and was used to assess the distinctiveness of the

123 haplogroups with the Species Delimitation Plugin in Geneious (Rosenberg, 2007; Masters, Fan \&

124 Ross, 2011). Within each of the three haplogroups, intraclade distances were significantly smaller than

125 interclade distances (Table 4). Rosenberg's $\mathrm{P}_{\mathrm{AB}}$ was 6.5E-18, 6.5E-18, 8.0E-34, for clades 1, 2, and 3,

126 respectively (Table 4), strongly supporting reciprocal monophyly of the three haplogroups. All three

127 haplogroups are clearly differentiated from the sister taxon Chthamalus proteus (Figure 2).

128 Haplogroups differed in their geographic distribution (Figure 3). Haplogroup 1 was present in

129 all New England sites and most southern sites, except Savannah and Tampa. Haplogroup 2 was well-

130 represented in the Massachusetts and Rhode Island sites, and also present in Virginia, but not in any of

131 the more southern sites. Haplogroup 3 was present in the Sandwich, Truro, and Woods Hole,

132 Massachusetts sites, but not in Rhode Island. It was the most abundant haplogroup in all of the

133 southern sites. In Savannah and Tampa, it was the only haplogroup found. The Mantel test indicated 
134 significant isolation by distance $(\mathrm{p}<0.001)$.

\section{Discussion}

137 Lineage diversity

138 Our results indicate significant genetic structure, with a break occurring between Virginia and

139 South Carolina. We recovered 3 well-supported, reciprocally monophyletic COI haplogroups. One

140 lineage was found in all locations, one in most locations (except Tampa and Savannah), and one in

141 Virginia and northward locations only. Additionally, we observed significant genetic structure between

142 northern and southern populations. This pattern - a cline between divergent clades - is similar to that

143 observed for other barnacles, including Balanus glandula along the California coast (Sotka et al.,

144 2004), Notochthamalus scabrosus along the Chilean coast (Zakas et al., 2009) and Chthamalus moro in

145 southeastern Asia (Wu et al., 2014).

146 A deep phylogeographic break for species like barnacles with high planktonic dispersal

147 potential may be due to several non mutually exclusive factors, including selection, cryptic speciation,

148 and the presence of dispersal barriers (Zakas et al., 2009). It is possible that $C$. fragilis belonging to

149 haplotype group 2 have characteristics that are less suited to southern locations. Additional research on

150 the physiology and ecology of $C$. fragilis are necessary to elucidate possible adaptive differences

151 between northern and southern populations.

152 The pattern of reciprocal monophyly and large between-clade relative to within-clade

153 divergences can sometimes be used to infer the existence of cryptic species (Govindarajan, Halanych \&

154 Cunningham, 2005). Mitochondrial COI is used as a marker in many population-level studies, and as a

155 genetic barcode to discriminate species (Bucklin, Steinke \& Blanco-Bercial, 2011). While evolutionary

156 rates differ between lineages, sequences originating from different individuals within a species show

157 less divergence (often less than 3\%, Bucklin, Steinke \& Blanco-Bercial, 2011) than sequences 
158 originating from individuals belonging to different species (often $>10 \%$, Bucklin, Steinke \& Blanco159 Bercial, 2011).

160 Cryptic speciation may be common among chthamalid barnacles. Dando and Southward (1980)

161 identified Chthamalus proteus as a cryptic species distinguishable only through molecular techniques

162 from C. fragilis using enzyme electrophoresis, and these results were supported by Wares (2001) and

163 Wares et al. (2009) using DNA sequences. In the Asian Chthamalus moro, Wu et al. (2014) observed

164 interpopulation COI variation 3.9-8.3\%, and inferred a cryptic speciation noting that population

165 comparisons at the upper end of that range were comparable to interspecific divergence in the

166 chthamalids Euraphia rhizophorae and E. eastropacensis ( 9\%; Wares, 2001), which were separated

167 by the rise of the Panamanian isthmus. However, the relatively short distances between our three $C$.

168 fragilis clades relative to C. proteus do not support separate species status for the clades.

169 Our observed phylogeographic transition between Virginia and South Carolina spans Cape

170 Hatteras, a region thought to be an important biogeographic boundary. Pappalardo et al. (2014) found

171 that Cape Hatteras is a northern boundary for many species, but less so a southern boundary. In our

172 dataset, this region is apparently a southern boundary for haplogroup 2. However, additional fine scale

173 sampling between Virginia and South Carolina, especially around Cape Hatteras, is necessary to

174 demarcate the location and nature of the break (e.g., Jennings et al., 2009).

175 Though a statistically significant pattern of isolation by distance (IBD) is detected in our data,

176 we are cautious about interpretation. The strict interpretation of IBD is an equilibrium pattern between

177 genetic drift and gene flow when migration is limiting, and so allele frequencies become divergent over

178 spatial distance. However, similar statistical patterns emerge by non-trivial disjunct distributions of

179 divergent lineages (Wares \& Cunningham 2005, Moyle, 2006), and may be driven by mechanisms of

180 vicariance and selection on these divergent lineages. Given the high potential for larval dispersal in 
181 C. fragilis, we simply note that this statistical signal indicates a limit to gene flow, which may or may 182 not be distinct from patterns of larval dispersal.

Northern expansion

Anthropogenic factors influence species distributions and population structure, which may

186 facilitate the northward expansion of C. fragilis (Carlton, Newman \& Pitombo, 2011). For barnacles,

187 larvae can be transported long distances in ballast water and adults on ship hulls (Godwin, 2003;

188 Zardus \& Hadfield, 2005; Carlton, Newman \& Pitombo, 2011). Coastal development is creating more

189 and novel habitats for barnacles as well as other hard substrate organisms in regions dominated by

190 sandy and muddy habitats where suitable substrate may have been previously limiting (Landschoff et

191 al., 2013). Furthermore, warmer temperatures associated with climate change are thought to facilite

192 poleward range expansions for many species (Barry et al., 1995; Zacherl, Gaines \& Lonhart. 2003;

193 Perry et al., 2005; Sunday et al., 2012) including barnacles (Southward, 1991; Dawson et al., 2010; De

194 Rivera et al., 2011).

195 Here, we sought to gain insight into the origin of the northern expansion of $C$. fragilis. Carlton,

196 Newman \& Pitombo. (2011) speculated that $C$. fragilis may have colonized Massachusetts by traveling

197 on ships bound for Woods Hole from South Carolina. Alternatively, non-transport related

198 anthropogenic factors may have facilitated expansion from the historical northern boundary in the mid-

199 Atlantic. Warmer temperatures may have shifted ecological interactions to favor C. fragilis (Wethey,

200 2002; Carlton, Newman \& Pitombo, 2011). Additionally, coastal development could have facilitated

201 stepwise northward dispersal. Construction of marinas, docks, jetties, seawalls, and other structures

202 provided hard substrate habitat that was not previously available in the typically sandy coastline

203 between Chesapeake Bay and New England. 
205 the northern part of its mid-19 $9^{\text {th }}$ century range. While our sample sizes are relatively small and we

206 analyze a single marker, the complete absence of any haplogroup 2 sequences south of Virginia

207 supports this hypothesis. Additional sampling in the mid-Atlantic region and analysis of multiple

208 genetic markers will be crucial for both providing additional testing of this hypothesis, and for

209 understanding the nature of the putative Cape Hatteras biogeographic break for C. fragilis.

210 As temperatures continue to increase, $C$. fragilis will likely continue to expand northward. Like

211 C. fragilis, S. balanoides appears to be shifting its range poleward; however the mechanism driving the

212 shift in $S$. balanoides is a range contraction in the southern part of its range (Jones, Southward \&

213 Wethey, 2012). Likely the range contraction is due to thermal stress in this boreo-arctic species, rather

214 than interaction with encroaching $C$. fragilis. Further research is needed to understanding the potential

215 impacts of range shifts on community dynamics (Sorte, Williams \& Carlton, 2010). Our genetic

216 analysis of $C$. fragilis, while limited, suggests that shifts in geographic distribution may be

217 accompanied by shifts in genetic composition (e.g., expansion of haplogroup 2). Understanding how

218 the population genetic composition is shifting, and how these changes may impact the overall

219 community structure, is critical for understanding the consequence of climate change on coastal

220 communities.

221

\section{Acknowledgements}

223 We thank V. Starczak (WHOI) for assistance with collecting barnacles, P. Polloni (WHOI) for

224 assistance with laboratory procedures, and T. Shank (WHOI) for use of his laboratory equipment. 


\section{References}

Barnes H, Barnes M. 1958. Further observations on self-fertilization in Chthamalus sp. Ecology 39(3):550.

Barry JP, Baxter CH, Sagarin RD, Gilman SE. 1995. Climate-related, long-term faunal changes in a California rocky intertidal community. Science 267:672-675.

Bucklin A, Steinke D, Blanco-Bercial L. 2011. DNA barcoding of marine metazoan. Annual Review of Marine Science 3(1):471-508.

Carlton JT. 2002. Bioinvasion ecology: assessing invasion impact and scale. In: Leppăkoski E, Gollasch S, Olenin S, eds. Invasive aquatic species of Europe: distribution, impacts, and management. Dordrecht: Kluwer Academic Publishers, 7-19.

Carlton JT, Newman WA, Pitombo FB. 2011. Barnacle invasions: introduced, cryptogenic, and range expanding Cirripedia of North and South America. In: Galil BS, Clark PF \& Carlton JT, eds. In the wrong place - Alien marine crustaceans: distribution, biology and impacts. Berlin: Springer - Verlag, 159-213.

Crisp D. 1950. Breeding and distribution of Chthamalus stellatus. Nature 166:311-312.

Dando PR, Southward AJ. 1980. A new species of Chthamalus (Crustacea: Cirripedia) characterized by enzyme electrophoresis and shell morphology: with a revision of other species of Chthamalus from the western shores of the Atlantic Ocean. Journal of the Marine Biological Association of the United Kingdom 60(3):787-831.

Darriba D, Taboada GL, Doallo R, Posada D. 2012. jModelTest 2: more models, new heuristics and parallel computing. Nature Methods 9:772.

Dawson MN, Grosberg RK, Stuart YE, Sanford E. 2010. Population genetic analysis of a recent range expansion: mechanisms regulating the poleward range limit in the volcano barnacle Tetraclita rubescens. Molecular Ecology 19(8):1585-1605. 
De Rivera CE, Steves BP, Fofonoff PW, Hines AH, Ruiz GM. 2011. Potential for high-latitude marine invasions along western North America. Diversity and Distributions 17(6):1198-1209.

251 Excoffier L, Lischer HEL. 2010. Arlequin suite ver 3.5: A new series of programs to perform 252

253 population genetics analyses under Linux and Windows. Molecular Ecology Resources 10:564567.

254 Folmer O, Black M, Hoeh W, Lutz R, Vrijenhoek R. 1994. DNA primers for amplification of mitochondrial cytochrome c oxidase subunit I from diverse metazoan invertebrates. Molecular Marine Biology and Biotechnology 3(5):249-299.

257 Geller JB, Darling JA, Carlton JT. 2010. Genetic perspectives on marine biological invasions. Annual Review of Marine Science 2:367-393.

259

Godwin LS. 2003. Hull fouling of maritime vessels as a pathway for marine species invasions to the Hawaiian Islands. Biofouling 19:123-131.

Govindarajan AF, Halanych KM, Cunningham CW. 2005. Mitochondrial evolution and phylogeography in the hydrozoan Obelia geniculata (Cnidaria). Marine Biology 146(2):213222.

Guindon S, Gascuel O. 2003. A simple, fast and accurate method to estimate large phylogenies by maximum-likelihood. Systematic Biology 52:696-704.

Harley CDG. 2011. Climate change, keystone predation, and biodiversity loss. Science 334:1124-1127.

Jennings RM, Shank TM, Mullineaux LS, Halanych KM. 2009. Assessment of the Cape Cod phylogeographic break using the bamboo worm Clymenella torquata reveals the role of regional water masses in dispersal. Journal of Heredity 100 (1):86-96.

Jensen JL, Bohonak, AJ, Kelley ST. 2005. Isolation by distance, web service. BMC Genetics 6:13. v.3.23. Available at http://ibdws.sdsu.edu/

Jones SJ, Southward AJ, Wethey DS. 2012. Climate change and historical biogeography of the 
barnacle Semibalanus balanoides. Global Ecology and Biogeography 21:716-724.

274 Landschoff J, Lackschewitz D, Kesy K, Reise K. 2013. Globalization pressure and habitat change:

Pacific rocky shore crabs invade armored shorelines in the Atlantic Wadden Sea. Aquatic Invasions 8(1):77-87.

Lang WH, Ackenhusen-Johns A. 1981. Seasonal species composition of barnacle larvae (Cirripedia: Thoracica) in Rhode Island waters, 1977-1978. Journal of Plankton Research 3(4):567-575.

Larkin MA, Blackshields G, Brown NP, Chenna R, McGettigan PA, McWilliam H, Valentin F,

Wallace IM, Wilm A, Lopez R, Thompson JD, Gibson TJ, Higgins DG. 2007. Clustal W and

Librado P, Rozas J. 2009. DnaSP v5: A software for comprehensive analysis of DNA polymorphism data. Bioinformatics 25:1451-1452

284 285

$$
\text { Clustal X version 2.0. Bioinformatics 23:2947-2948. }
$$

Masters BC, Fan V, Ross HA. 2011. Species Delimitation - a Geneious plugin for the exploration of species boundaries. Molecular Ecology Resources 11:154-157.

Miller KM, Blower SM, Hedgecock D, Roughgarden J. 1989. Comparison of larval and adult stages of Chthamalus dalli and Chthamalus fissus (Cirripedia: Thoracica). Journal of Crustacean Biology 9(2):242-256.

Moyle LC. 2006. Correlates of genetic differentiation and isolation by distance in 17 congeneric Silene species. Molecular Ecology 15(4):1067-1081.

Pappalardo P, Pringle JM, Wares JP, Byers JE. 2014. The location, strength, and mechanisms behind marine biogeographic boundaries of the east coast of North America. Ecography 38:001-010.

Perry AL, Low PJ, Ellis JR, Reynolds JD. 2005. Climate change and distribution shifts in marine fishes. Science 308:1912-1915.

Rosenberg NA. 2007. Statistical tests for taxonomic distinctiveness from observations of monophyly. Evolution 61:317-323. 
297 Sorte CJB, Williams SL, Carlton JT. 2010. Marine range shifts and species introduction: comparative spread rates and community impacts. Global Ecology and Biogeography 19:303-316.

Sotka EE, Wares JP, Barth JA, Grosberg RK, Palumbi SR. 2004. Strong genetic clines and 300 geographical variation in gene flow in the rocky intertidal barnacle Balanus glandula. Molecular Ecology 13:2143-2156.

Southward AJ. 1991. Forty years of changes in species composition and population density of barnacles on a rocky shore near Plymouth, England, UK. Journal of the Marine Biological Association of the United Kingdom 71:495-514.

Sumner FB. 1909. On the occurrence of the littoral barnacle Chthamalus stellatus (Poli) at Woods Hole, Mass. Science 30:373-374.

Sunday JM, Bates AE, Dulvy NK. 2012. Thermal tolerance and the global redistribution of animals. Nature Climate Change 2:686-690.

Valentine JW. 1966. Numerical analysis of marine molluscan ranges on the extratropical northeastern Pacific shelf. Limnology and Oceanography 11:198-211.

Wares JP. 2001. Patterns of speciation inferred from mitochondrial DNA in North American Chthamalus (Cirripedia: Balanomorpha: Chthamaloidea). Molecular Phylogenetics and Evolution 18(1):104-116.

319 Wells HW. 1966. Barnacles of the northeaster Gulf of Mexico. Quarterly Journal of the Florida 
321 Wethey DS. 2002. Biogeography, competition, and microclimate: the barnacle Chthamalus fragilis in New England. Integrative and Comparative Biology 42:872-880.

323 Wu TH, Tsang LM, Chan BK, Chu KH. 2014. Cryptic diversity and phylogeography of the islandassociated barnacle Chthamalus moro in Asia. Marine Ecology doi: 10.1111/maec.12146.

325 Zacherl D, Gaines SD, Lonhart SI. 2003. The limits to biogeographical distributions: insights from the northward range extension of the marine snail, Kelletia kelletii (Forbes, 1852). Journal of

Zardus JD, Hadfield MG. 2005. Multiple origins and incursions of the Atlantic barnacle Chthamalus proteus in the Pacific. Molecular Ecology 14(12):3719-3733.

330 Zakas, C, Binford J, Navarrete SA, Wares JP. 2009. Restricted gene flow in Chilean barnacles reflects an oceanographic and biogeographic transition zone. Marine Ecology Progress Series 394:165177.

333 Zullo VA. 1963. A preliminary report on systematics and distribution of barnacles (Cirripedia) of the Cape Cod region, Systematic Ecology Program, Contribution no. 3. Marine Biological Laboratory, Woods Hole. 
Table 1 (on next page)

Summary statistics

Table 1: Summary statistics calculated in DnaSP. None of the Tajima's D values were significant. $\mathrm{N}=$ number of individuals; $\mathrm{H}=$ number of haplotypes; $\mathrm{Hd}=$ haplotype diversity; $\mathrm{Pi}=$ nucleotide diversity; SAND = Sandwich, Massachusetts; TR = Truro, Massachusetts; WH $=$ Woods Hole, Massachusetts; RWU = Bristol, Rhode Island; VA = Gloucester Point, Virginia; SC = Charleston, South Carolina; SI = Sapelo Island, Georgia; SA = Savannah, Georgia; SK = Summerland Key, Florida; KL = Key Largo, Florida; TF = Tampa, Florida. 


\begin{tabular}{|l|l|l|l|l|l|l|}
\hline Collection site & $\mathbf{n}$ & $\mathbf{H}$ & Hd & Pi & Tajima's D & Fu's Fs \\
\hline SAND & 11 & 11 & 1 & 0.01640 & -0.95411 & -4.172 \\
\hline TR & 9 & 9 & 1 & 0.01749 & -0.30109 & -2.642 \\
\hline WH & 12 & 11 & 0.985 & 0.01750 & -0.56516 & -2.648 \\
\hline RWU & 11 & 8 & 0.945 & 0.01222 & -0.01230 & -0.431 \\
\hline VA & 11 & 10 & 0.982 & 0.01886 & -0.27640 & -1.849 \\
\hline SC & 12 & 11 & 0.985 & 0.01508 & -0.31326 & -3.116 \\
\hline SI & 7 & 7 & 1 & 0.01725 & -0.23160 & -1.463 \\
\hline SA & 7 & 7 & 1 & 0.01041 & -1.43806 & -2.449 \\
\hline SK & 7 & 7 & 1 & 0.01717 & -0.63213 & -1.471 \\
\hline KL & 14 & 14 & 1 & 0.01750 & -0.64068 & -6.227 \\
\hline TF & 7 & 6 & 0.952 & 0.00792 & -0.46339 & -1.188 \\
\hline Total & & & & & & \\
\hline
\end{tabular}

3 
Table 2 (on next page)

Population paiwise $\mathrm{F}_{\mathrm{ST}}$ values.

Table 2: Population pairwise $F_{S T}$ values. Distance method: pairwise distance. Negative values converted to 0 . Significant values $(p<0.05)$ in bold. 


\begin{tabular}{|l|l|l|l|l|l|l|l|l|l|l|}
\hline & WH & RI & SC & TF & SI & VA & TR & SN & KL & SK \\
\hline WH & & & & & & & & & & \\
\hline RI & 0 & & & & & & & & & \\
\hline SC & $\mathbf{0 . 1 5 3}$ & $\mathbf{0 . 2 9 9}$ & & & & & & & & \\
\hline TF & $\mathbf{0 . 3 4 9}$ & $\mathbf{0 . 4 9 7}$ & $\mathbf{0 . 1 1 8}$ & & & & & & & \\
\hline SI & $\mathbf{0 . 1 5 4}$ & $\mathbf{0 . 3 1 0}$ & 0 & 0.055 & & & & & & \\
\hline VA & 0.085 & $\mathbf{0 . 1 8 6}$ & 0.003 & $\mathbf{0 . 1 0 9}$ & 0 & & & & & \\
\hline TR & 0.031 & 0.053 & 0.078 & $\mathbf{0 . 2 4 0}$ & 0.062 & 0 & & & & \\
\hline SAND & 0 & 0 & $\mathbf{0 . 2 0 2}$ & $\mathbf{0 . 3 8 1}$ & $\mathbf{0 . 2 0 5}$ & 0.103 & 0 & & & \\
\hline KL & 0.100 & $\mathbf{0 . 2 4 1}$ & 0 & 0.120 & 0 & 0.018 & 0.080 & $\mathbf{0 . 1 5 4}$ & & \\
\hline SK & $\mathbf{0 . 1 5 8}$ & $\mathbf{0 . 3 0 6}$ & 0 & 0.044 & 0 & 0 & 0.074 & $\mathbf{0 . 2 0 3}$ & 0 & \\
\hline SA & $\mathbf{0 . 3 9 0}$ & $\mathbf{0 . 5 3 7}$ & 0.103 & $\mathbf{0 . 1 1 2}$ & 0.023 & 0.137 & $\mathbf{0 . 2 6 7}$ & $\mathbf{0 . 4 3 0}$ & $\mathbf{0 . 1 4 3}$ & 0.065 \\
\hline
\end{tabular}

3

4

5 
Table 3 (on next page)

Analysis of Molecular Variance results

Table 3: Analysis of Molecular Variance (AMOVA) results. 


\begin{tabular}{|l|l|l|l|l|}
\hline Source of variation & d.f. & $\begin{array}{l}\text { Sum of } \\
\text { squares }\end{array}$ & $\begin{array}{l}\text { Variance } \\
\text { components }\end{array}$ & $\begin{array}{l}\text { Percentage of } \\
\text { variation }\end{array}$ \\
\hline $\begin{array}{l}\text { Among } \\
\text { populations }\end{array}$ & 10 & 121.666 & $0.75549 \mathrm{Va}$ & 13.61 \\
\hline Within populations & 97 & 464.982 & $4.79363 \mathrm{Vb}$ & 86.39 \\
\hline Total & 107 & 586.648 & 5.54912 & \\
\hline Fixation Index & $\begin{array}{l}\mathrm{F}_{\mathrm{ST}}: \\
0.13615\end{array}$ & & & \\
\hline
\end{tabular}

3

4 


\section{Table 4(on next page)}

Species delimitation results

Table 4: Species delimitation results. Clade support is posterior probability from the Bayesian analysis for the node defining the clade (Fig 1). 


\begin{tabular}{|l|l|l|l|}
\hline & Clade 1 & Clade 2 & Clade 3 \\
\hline Closest clade & 2 & 1 & 2 \\
\hline Intra Dist & 0.008 & 0.009 & 0.010 \\
\hline Inter Dist - closest & 0.020 & 0.020 & 0.024 \\
\hline Intra/Inter & 0.39 & 0.44 & 0.40 \\
\hline P ID (Strict) & $0.87(0.82,0.93)$ & $0.86(0.81,0.91)$ & $0.87(0.82,0.92)$ \\
\hline P ID (Liberal) & $0.96(0.94,0.99)$ & $0.96(0.93,0.99)$ & $0.96(0.94,0.99)$ \\
\hline Av(MRCA-tips) & 0.0057 & 0.0050 & 0.0086 \\
\hline P(randomly distinct) & 1.00 & 0.51 & 1.00 \\
\hline Clade support & 0.94 & 0.98 & 1 \\
\hline Rosenberg's P(AB) & $6.5 \mathrm{E}-18$ & $6.5 \mathrm{E}-18$ & $8.0 \mathrm{E}-34$ \\
\hline
\end{tabular}

3 
Table 5(on next page)

Distribution of individuals in haplogroups

Table 5: Number of individuals falling in haplogroups 1, 2, and 3 for each sampling location. SAND = Sandwich, Massachusetts; TR = Truro, Massachusetts; $W H=$ Woods Hole, Massachusetts; RWU = Bristol, Rhode Island; VA = Gloucester Point, Virginia; SC = Charleston, South Carolina; SI = Sapelo Island, Georgia; SA = Savannah, Georgia; SK = Summerland Key, Florida; KL = Key Largo, Florida; TF = Tampa, Florida. 


\begin{tabular}{|l|l|l|l|}
\hline Sampling & Clade 1 & Clade 2 & Clade 3 \\
\hline SAND & & & \\
\hline TR & 4 & 6 & 1 \\
\hline WH & 1 & 5 & 3 \\
\hline RWU & 6 & 4 & 2 \\
\hline VA & 4 & 7 & 0 \\
\hline SC & 2 & 3 & 6 \\
\hline SI & 4 & 0 & 8 \\
\hline SA & 2 & 0 & 5 \\
\hline SK & 0 & 0 & 7 \\
\hline KL & 2 & 0 & 5 \\
\hline TF & 6 & 0 & 8 \\
\hline
\end{tabular}

3

4

5 


\section{1}

Neighbor-joining topology

Figure 1: Neighbor-joining topology generated using HKY distances. The three major haplogroups are highlighted and the posterior probabilities obtained in the Bayesian analysis for the nodes defining these clades are given. SAND = Sandwich, Massachusetts; TR = Truro, Massachusetts; $\mathrm{WH}=$ Woods Hole, Massachusetts; RWU = Bristol, Rhode Island; VA = Gloucester Point, Virginia; SC = Charleston, South Carolina; SI = Sapelo Island, Georgia; SA = Savannah, Georgia; SK = Summerland Key, Florida; KL = Key Largo, Florida; TF = Tampa, Florida. 


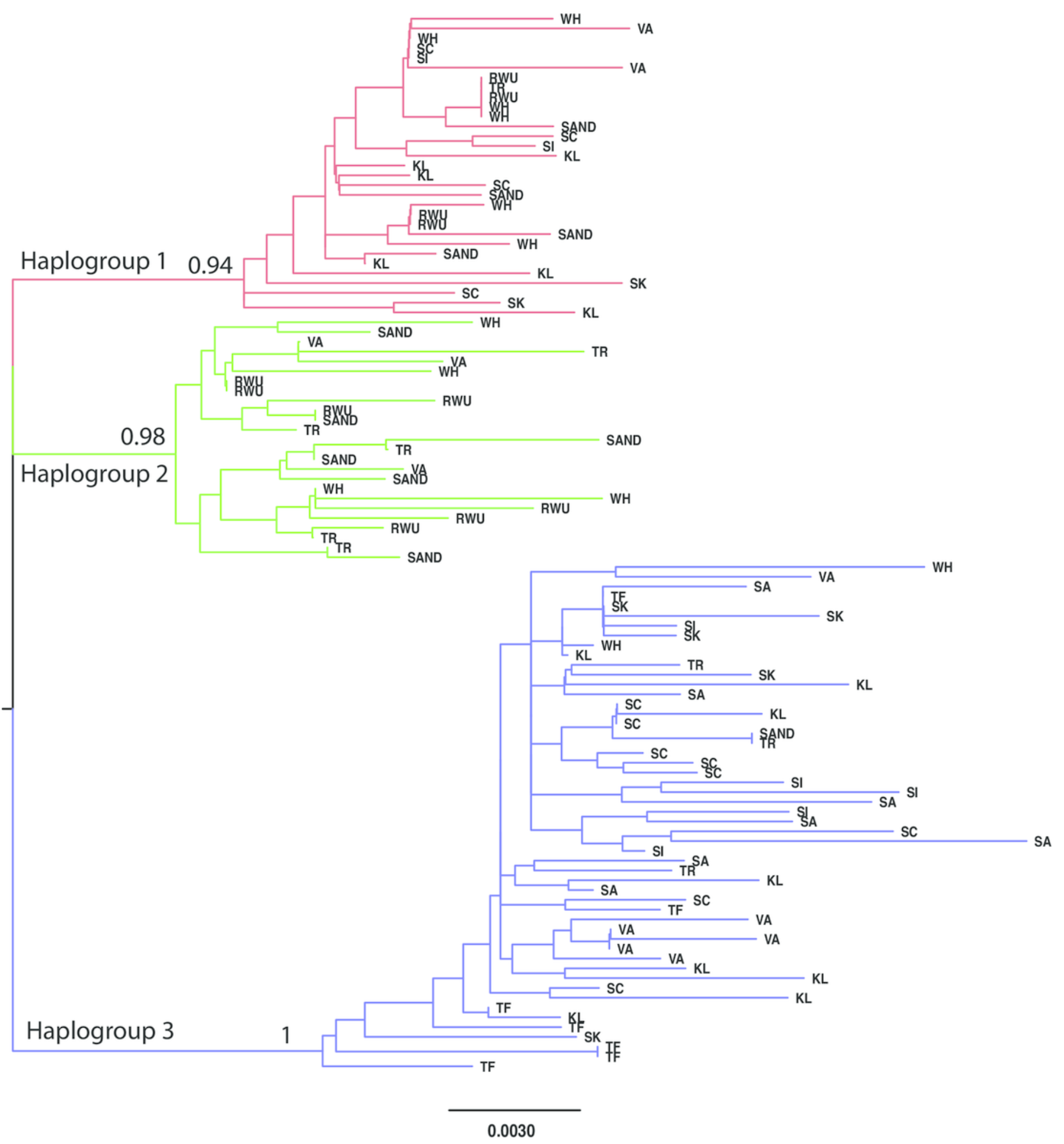


2

Comparison with Chthamalus proteus.

Figure 2: Comparison with Chthamalus proteus. Midpoint-rooted neighbor-joining topology generated using HKY distances.

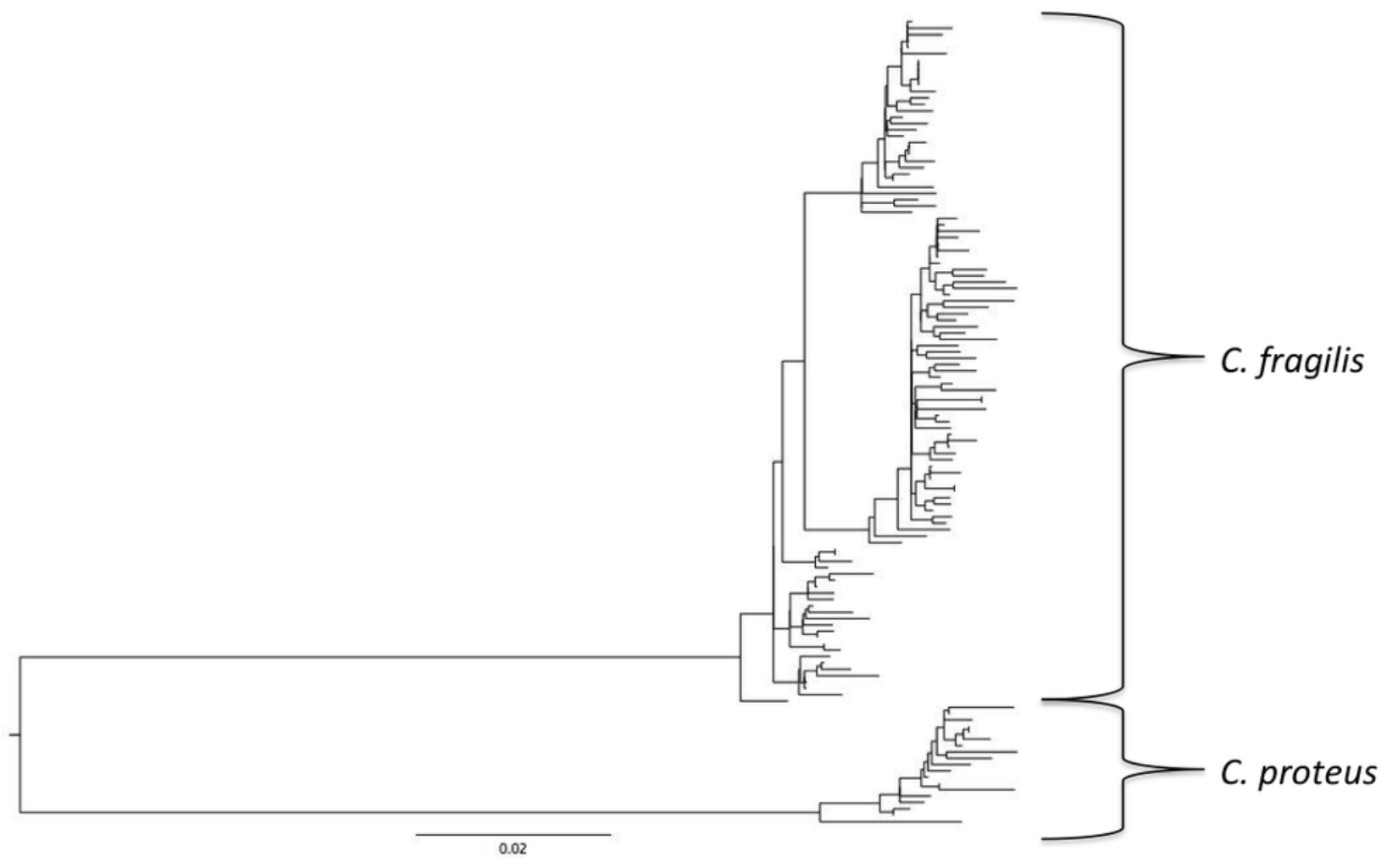


3

Geographic distribution of haplogroups.

Figure 3: Geographic distribution of the three major haplogroups.

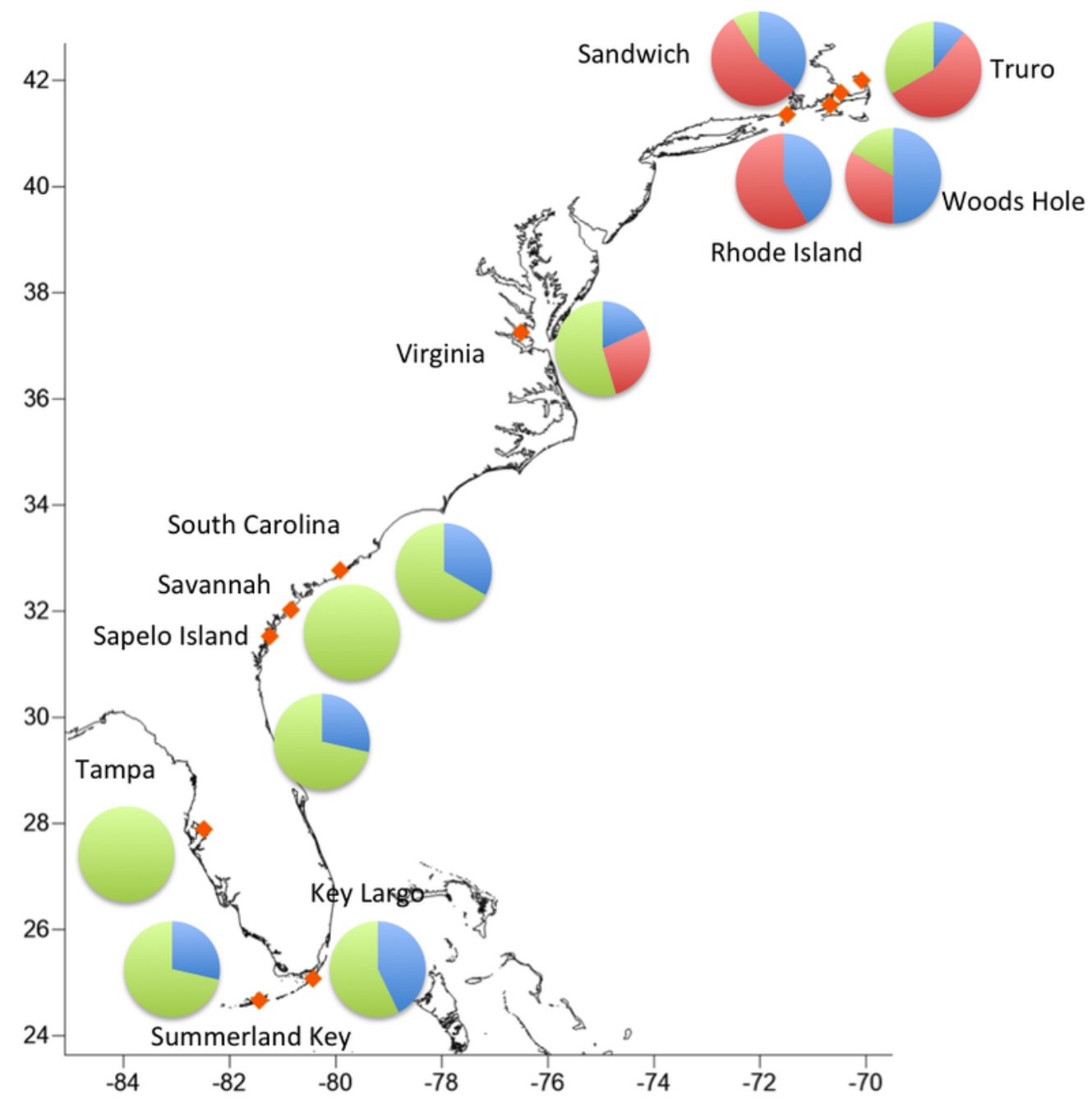

